\title{
MANAJEMEN EMOSI SESUAI TUNTUTAN KERJA (EMOTIONAL LABOR) DITINJAU DARI TIPE KEPRIBADIAN PADA WIRANIAGA
}

\author{
Ika Zenita Ratnaningsih
}

\author{
Fakultas Psikologi Universitas Diponegoro \\ J1. Prof. Soedharto SH Tembalang Semarang 50275 \\ ikazenita@undip.ac.id
}

\begin{abstract}
This study aims to investigate the difference in management of emotions as the demands of work (emotional labor) between extrovert and introvert salespeople. Subjects comprised 92 salespeople of the department store "X" (82 women; 10 men), aged 18-40 years (mean of age 22 years). In average, subjects had finished high school/equivalent. The average tenure is 2.5 years. Data were collected using two scales: Eysenck Personality Questionnaire/EPQ (22-items; $\alpha=.865)$ and Emotional Labor Scale (11-items; $\alpha=.787)$. The results of t-test showed that introvert salespeople scored significantly higher than the extrovert salespeople $\left(M_{\text {introvert }}=36.08\right.$; $\left.M_{\text {extrovert }}=33.67 ; t=3.50 ; p=.001\right)$. It can be concluded that the introvert salespeople have better emotional labor than the extrovert salespeople.
\end{abstract}

Keywords: personality type, emotional labor, introvert, extrovert, salespeople

\begin{abstract}
Abstrak
Penelitian ini bertujuan untuk mengetahui perbedaan manajemen emosi sesuai tuntutan kerja (emotional labor) pada wiraniaga yang memiliki tipe kepribadian extrovert dan introvert. Subjek penelitian adalah wiraniaga di Departement Store X berjumlah 92 orang (82 wanita; 10 pria), berusia antara 18-40 tahun (rerata usia 22 tahun). Pada umumnya subjek memiliki latar belakang pendidikan SMA/sederajat, dengan rerata masa kerja selama 2,5 tahun. Pengumpulan data menggunakan dua buah skala, yaitu Eysenck Personality Questionnaire/EPQ (22 aitem; $\alpha=0,865$ ) dan Skala Emotional Labor (11 aitem; $\alpha=0,787)$. Hasil analisis data menggunakan uji-t menunjukkan bahwa rerata emotional labor wiraniaga yang memiliki kecenderungan tipe kepribadian introvert lebih tinggi daripada wiraniaga yang memiliki kecenderungan tipe kepribadian extrovert $\left(M_{\text {introvert }}=36,08\right.$; $\left.M_{\text {extrovert }}=33,67 ; t=3,50 ; p=0,001\right)$. Dengan demikian dapat disimpulkan bahwa wiraniaga dengan kecenderungan tipe kepribadian introvert lebih mampu dalam melakukan manajemen emosi sesuai tuntutan pekerjaan dibanding wiraniaga dengan kecenderungan tipe kepribadian ekstrovert.
\end{abstract}

Kata Kunci: tipe kepribadian, emotional labor, introvert, extrovert, wiraniaga

\section{PENDAHULUAN}

Persaingan yang ketat dalam dunia industri pada dekade ini, mendorong perusahaan untuk memberikan perhatian kepada kegiatan pemasaran dan pelayanan yang memberikan kepuasan bagi para pengguna produk. Untuk memperkuat citra merek, salah satu cara yang digunakan adalah dengan menjalin hubungan interpersonal dengan para konsumen secara langsung (Berry, 2000). Karyawan yang bertugas melakukan promosi dan penjualan dikenal dengan sebutan wiraniaga (KBBI Online, 2015), yaitu karyawan yang bekerja menjual dan mempromosikan produk. Kemampuan wiraniaga dalam menawarkan, mempromosikan dan menjual produk kepada konsumen merupakan hal yang penting bagi perusahaan, karena di tangan mereka citra sebuah produk akan dapat dikenali secara langsung oleh konsumen.

Terdapat beberapa hal yang membuat jenis pekerjaan wiraniaga merupakan pekerjaan yang unik. Menurut Permata (2007), wiraniaga dituntut untuk berpenampilan menarik, berperilaku ramah, mampu mempersuasi dan mengatur emosi sehingga 
hanya menunjukkan emosi positif pada pelanggan. Tantangan pekerjaan ini adalah pencapaian target, pandangan masyarakat yang memandang rendah pekerjaan sales dan pelecehan seksual yang biasanya terjadi pada wiraniaga berjenis kelamin wanita. Pekerjaan sebagai wiraniaga juga memiliki resiko berupa penolakan dari konsumen.

Pada saat bekerja, wiraniaga dituntut untuk dapat mengatur emosinya agar wajahnya selalu berekspresi positif seperti tersenyum. Ekspresi emosi negatif seperti cemberut dan sedih dilarang untuk ditampilkan saat bekerja karena dapat mengakibatkan situasi yang tidak menyenangkan pada konsumen. Hal ini menyebabkan adanya perbedaan emosi antara yang dirasakan dan ditampilkan. Fenomena untuk melakukan pengaturan emosi di tempat kerja yang dilakukan oleh wiraniaga disebut sebagai emotional labor, yaitu manajemen emosi untuk menciptakan wajah dan gerak tubuh yang dapat diobservasi agar sesuai dengan tuntutan perusahaan (Hochschild, 2012). Manajemen emosi ini dilakukan atas dasar adanya gaji atau upah, oleh karena itu mempunyai nilai tukar. Mengatur emosi pada karyawan pelayanan atau garda depan salah satu cara yang dilakukan untuk mencapai tujuan perusahaan (Arvey, dalam Grandey, 2000).

Beberapa penelitian menunjukkan bahwa emotional labor berpengaruh positif terhadap kinerja karyawan pada beberapa bidang. Penelitian menunjukkan adanya hubungan positif antara emotional labor dengan hasil kerja karyawan pada bidang perhotelan (Chu, 2002), kepuasan kerja karyawan bidang pelayanan (Johnsons, 2004), kepuasan klien terhadap instruktur fitness (Collishaw, Dyer, \& Boies, 2008), kesejahteraan karyawan pada perawat (Nurdiyani, 2009), kepuasan kerja pada tour leader (Torland, 2012), dan kepuasan kerja dan komitmen organisasi (Cho, Rutherford, \& Park, 2013).
Permata (2007) menemukan beberapa faktor yang mempengaruhi manajemen emosi saat bekerja (emotional labor) yang dapat dikategorikan menjadi dua, yaitu faktor dari dalam diri individu dan faktor lingkungan. Faktor dalam diri individu, mencakup pemahaman akan tuntutan pekerjaan dan profesionalitas, sedangkan faktor lingkungan dapat dibagi menurut lingkungan organisasi yang meliputi pengawasan dari atasan dan rekan kerja serta gaji, dan lingkungan konsumen. Hasil penelitian Permata (2007) tersebut menegaskanadanya penyebab yang bersifat individu dalam manajemen emosi sesuai tuntutan kerja. Saat bekerja, karyawan dituntut untuk berperilaku bukan seperti dirinya pribadi, akan tetapi sebagai perwakilan perusahaan (Hochschild, 2012). Artinya, emosi yang merupakan hal pribadi dan dilakukan atas dasar kehendak sendiri, dalam hal ini menjadi bagian dari publik dan diatur oleh perusahaan serta diawasi oleh supervisor, sehingga profesionalitas kerja diukur dan dilihat dari kemampuan untuk mengatur emosi sesuai tuntutan kerja.

Menurut Hochschild (2012), terdapat dua cara dalam melakukan proses manajemen emosi sesuai tuntutan kerja (emotional labor), yaitu akting permukaan (surface acting) dan akting mendalam (deep acting). Surface acting merupakan keadaan seseorang meregulasi ekspresi emosinya dengan cara menyembunyikan maupun memalsukan emosinya, yaitu individu memasang ekspresi wajah seperti yang dituntut pekerjaan misalnya tersenyum kepada konsumen yang menyebalkan. Cara yang kedua adalah deep acting yaitu keadaan dimana individu secara sadar mengatur emosinya untuk dapat mengekspresikan suatu emosi tertentu sehingga ia benar-benar merasakan emosi tersebut. Konsep deep acting berhubungan dengan pemikiran kognitif yaitu mengevaluasi kembali situasi yang dihadapi (re-appraisal), membayangkan situasi lain 
(imaging), serta berbicara kepada diri sendiri (self talk). Lebih lanjut Zapf (2002) menyebutkan bahwa emotional labor ditandai dengan proses tatap muka atau suara untuk menyuarakan interaksi, adanya upaya untuk mempengaruhi orang lain dan adanya ekspresi emosi yang harus mengikuti aturan-aturan tertentu.

Hoschchild (2012) juga mengemukakan bahwa manajemen emosi ini membutuhkan usaha untuk melakukannya. Manajemen emosi ini dapat menyebabkan kerugian dan tidak menyenangkan bagi karyawan sehingga dapat menyebabkan burnout dan stres (Grandey, 2000; Modekurti-mahato, Kumar, \& Raju, 2014). Perspektif lain dari Ashforth dan Humphrey (dalam Grandey, 2000) memandang emotional labor sebagai suatu perilaku menunjukkan ekspresi emosi yang sesuai dengan tujuan tertentu sebagai bentuk manajemen impresi dalam organisasi. Pernyataan tersebut lebih menekankan pada perilaku yang dapat diamati bukan pada manajemen perasaan. Artinya, emosi yang dirasakan dalam bekerja tidaklah penting bagi perusahaan, akan tetapi yang ditekankan adalah perilaku mengeluarkan ekspresi emosi yang dapat dilihat oleh konsumen. Selain itu, Ashforth dan Humphrey (dalam Grandey, 2000) juga menganggap emotional labor sebagai suatu rutinitas, sehingga bukan sumber dari stres.

Perspektif lainnya dikemukakan oleh Morris dan Feldman (dalam Grandey, 2000) menyebutkan emotional labor sebagai segala usaha, perencanaan, dan kontrol yang diperlukan untuk mengekspresikan segala emosi yang diinginkan organisasi selama transaksi interpersonal di tempat kerja. Menurut perspektif ini, emotional labor lebih ditentukan oleh lingkungan sosial. Lebih lanjut Morris dan Feldman (dalam Grandey, 2000) merumuskan empat dimensi dalam emotional labor, yaitu: a) frekuensi interaksi (berapa lama, berapa intens, dan berapa sering); b) attentiveness (intensitas emosi, durasi interaksi) dengan dimensi minor berupa surface acting dan deep acting; c) variasi emosi yang diharapkan perusahaan; serta d) emotional dissonance (perbedaan antara emosi yang dirasakan dan diekspresikan).

Manajemen emosi sesuai tuntutan kerja (emotional labor) merupakan konsep yang berbeda dengan regulasi emosi di tempat kerja (regulation emotion at work). Regulasi emosi di tempat kerja bersifat lebih luas yaitu karyawan melakukan manajemen emosi walaupun tidak dituntut perusahaan. Pengaturan emosi dalam konteks emotional labor adalah sesuatu yang bersifat dituntut oleh perusahaan dan melakukannya adalah bagian dari tugas pekerjaan. (Grandey, 2000). Emotional labor bagi karyawan bagian pelayanan adalah suatu hal yang sangat penting dan berdampak pada kesuksesan organisasi, kinerja karyawan serta kepuasan pelanggan.

Emotional labor dapat berdampak negatif terhadap karyawan berupa stres, burnout, absensi yang tinggi, dan ketidakpuasan kerja karena terlalu sering menekan emosi negatifnya (Hochschild, 2012). Hal ini terjadi pada sebagian karyawan yang mengalami kesulitan untuk meregulasi emosinya dan merasa tertekan karena harus selalu berekspresi positif. Sebaliknya, sebagian karyawan menunjukkan kenaikan kepuasan kerja selama melakukan ekspresi positif dalam pekerjaannya dan merasa dirinya mencapai kepuasan personal yang baik (Brotheridge \& Grandey, 2002).

Penyebab munculnya manajemen emosi sesuai tuntutan kerja juga didukung oleh banyak faktor yaitu faktor dari individu seperti kepribadian maupun faktor situasional seperti rekan kerja, atasan serta konsumen. Salah satu hal yang mampu membedakan individu satu dan yang lain dalam konteks pekerjaan adalah 
kepribadian. Allport (dalam Suryabrata, 2002) menyebutkan bahwa kepribadian merupakan organisasi dinamis dalam individu sebagai sistem psikofisis yang menentukan caranya yang khas dalam menyesuaikan diri terhadap lingkungannya. Definisi tersebut menyiratkan bahwa kepribadian sangat mempengaruhi perilaku individu. Sementara itu, Eysenck (dalam Suryabrata, 2002) memberikan definisi kepribadian sebagai keseluruhan pola perilaku baik yang aktual maupun potensial dari individu yang ditentukan oleh faktor bawaan dan lingkungan. Menurut Cattel (dalam Hall \& Lindzey, 1999) kepribadian dipandang sebagai suatu hal yang dapat memungkinkan prediksi tentang apa yang akan dilakukan individu dalam situasi tertentu berkenaan pada perilaku yang menyeluruh baik perilaku yang tampak atau tidak tampak.

Kepribadian dapat ditinjau dari berbagai macam pendekatan, salah satu diantaranya berdasarkan perspektif tipologi. Jung merupakan salah seorang ilmuwan yang menemukan tipologi yang membedakan kepribadian seseorang. Ia membedakan kepribadian dalam dua tipe, yaitu introvert dan extravert. Tipe kepribadian ini kemudian oleh Eysenck dikembangkan lebih lanjut. Eysenck membedakan kepribadian dalam dua tipe, yaitu introvert dan extravert, untuk menyatakan adanya perbedaan dalam reaksi-reaksi terhadap lingkungan dan dalam tingkah laku (Suryabrata, 2000).

Menurut Jung (dalam Hall \& Lindzey, 1999), individu yang bertipe kepribadian introvert orientasi jiwanya terarah ke dalam dirinya, suka menyendiri, menjaga jarak terhadap orang lain, cenderung pemalu, membutuhkan waktu agak lama dalam penyesuaian diri terhadap lingkungan, perasaannya di bawah kontrol yang ketat, agak pesimis dan menjunjung nilai-nilai etis. Individu yang bertipe kepribadian extrovert orientasi jiwanya terarah ke luar dirinya, bersifat sosiabel, membutuhkan orang lain untuk diajak berbicara dan tidak menyukai aktifitas menyendiri, menyukai perangsangan, menyukai tindakan berisiko secara tiba-tiba, umumnya bersifat impulsive, menyukai perubahan, cenderung agresif dan perasaannya tidak di bawah kontrol yang ketat. Menurut Eysenck, setiap individu memiliki kecenderungan untuk tergolong ke dalam salah satu tipe kepribadian tersebut.

Eysenck \& Wilson (dalam Kuntadi, 2004), menyatakan hal yang senada, bahwa terdapat ciri-ciri tingkah laku yang membedakan tipe kepribadian extrovert dan introvert menurut faktor-faktor kepribadian yang mendasarinya. Selain dilihat dari aktivitas, interaksi sosial, keberanian mengambil resiko, dan cara pengambilan keputusan, ditambahkan tiga hal lainnya yaitu ekspresi emosi, pemikiran yang introspektif, dan tanggung jawab terhadap suatu pekerjaan. Kecenderungan tipe kepribadian ekstrovert - introvert menyatakan adanya perbedaan-perbedaan reaksi terhadap lingkungan, sekaligus menggambarkan keunikan individu dalam bertingkah laku terhadap suatu stimulus (Suryabrata, 2002).

Tipe kepribadian extravert dan introvert merupakan suatu dimensi yang bergerak dari satu ujung ke ujung yang lain pada suatu kontinum. Eysenck (dalam Suryabrata, 2000) juga menyatakan bahwa kecenderungan tipe kepribadian extrovert dan introvert tersebut bekerja saling melengkapi satu sama lain yang berorientasi pada keseimbangan jiwa individu. Berdasarkan uraian di atas, dapat disimpulkan bahwa tipe kepribadian seseorang akan mempengaruhi pola perilakunya dalam menghadapi situasi tertentu, termasuk dalam melakukan manajemen emosi sesuai tuntutan kerja. Maka hipotesis yang diajukan dalam 
penelitian ini adalah "Apakah ada perbedaan emotional labor ditinjau dari tipe kepribadian introvert dan ekstrovert?"

\section{METODE PENELITIAN}

Jumlah subjek yang terlibat dalam penelitian ini adalah 92 orang karyawan di sebuah Departement Store X di Semarang, terdiri dari 82 karyawan wanita, dan 10 karyawan laki - laki. Teknik pengambilan sampel dilakukan secara convenience sampling. Rata-rata masa kerja di Departement Store X adalah 2,5 tahun. Pendidikan terakhir subjek rata-rata adalah SMA/sederajat. Usia subjek berkisar antara 18 - 40 tahun, dengan rata-rata usia 22 tahun.

Untuk mengungkap tipe kepribadian, digunakan skala extrovert-introvert milik Eysenck yaitu Eysenck Personality Questionaire (EPQ). Skala ini digunakan untuk mengungkap tipe kepribadian seseorang apakah ia termasuk memiliki kecenderungan extrovert atau introvert. Skala EPQ disusun berdasarkan tujuh aspek yang mengungkap kecenderungan extrovert-introvert, yaitu (1) Aktivitas (activity); (2) Kemampuan sosial (sociability); (3) Pengambilan risiko (risktaking); (4) Impulsivitas (impulsiveness); (5) Keterbukaan ekspresi (expresiveness); (6) Refleksivitas (reflectiveness); (7) Tanggung jawab (responsibility) ( Eysenck \& Wilson, dalam Kuntadi, 2004).

Skala EPQ yang digunakan dalam penelitian merupakan adaptasi dari skala EPQ yang digunakan oleh Kuntadi (2004) dalam penelitiannya. Setelah diuji coba kembali, skala yang digunakan pada penelitian ini terdiri dari 22 aitem valid, dengan koefisien reliabilitas $(\alpha)$ sebesar 0,865 . Skor yang didapatkan dari tiap subjek dikategorikan menjadi kategori 1 (introvert) dan kategori 2 (ekstrovert), dasar pengkategorian menggunakan skor $\mathrm{z}$.
Untuk mengungkap manajemen emosi sesuai tuntutan kerja (emotional labor) digunakan Skala Emotional Labor yang disusun oleh peneliti dengan mengacu pada teori Emotional Labor yang dikemukakan oleh Hochschild (2012) yang terdiri dari dua aspek yaitu, surface acting dan deep acting. Hasil analisis seleksi aitem menghasilkan 11 aitem valid dengan koefisien reliabilitas $(\alpha)$ sebesar 0,787. Data yang diperoleh melalui kedua skala di atas, selanjutnya dianalisis menggunakan uji $\mathrm{t}$ ( $t$ test) yang bertujuan untuk melihat perbedaan manajemen emosi sesuai tuntutan kerja pada wiraniga yang memiliki tipe kepribadian introvert dan ekstrovert.

\section{HASIL DAN PEMBAHASAN}

Berdasarkan hasil analisa lebih lanjut, dari 92 subjek penelitian, dapat diidentifikasi bahwa 50 subjek termasuk introvert dan 42 ekstrovert $\left(\mathrm{M}_{\text {introvert }}=36,08 ; \mathrm{M}_{\text {extrovert }}=\right.$ 33,67). Untuk Skala Emotional Labor, dari data empirik diketahui bahwa skor maksimum adalah 44, dan skor minimum adalah 27 , dengan rerata 34,98 dan deviasi standar 3,573.

Hasil analisis data menunjukkan bahwa ada perbedaan emotional labor yang signifikan antara tipe kepribadian introvert ekstrovert $(\mathrm{t}=3,50, \mathrm{p}=0.001)$. Lebih lanjut dapat diamati bahwa rerata emotional labor pada kecenderungan tipe kepribadian introvert lebih tinggi daripada tipe kepribadian ekstrovert. Hasil tersebut menunjukkan bahwa wiraniaga dengan kecenderungan tipe kepribadian introvert lebih mampu / memiliki kemampuan lebih baik dalam melakukan manajemen emosi sesuai tuntutan pekerjaan dibanding wiraniaga dengan kecenderungan tipe kepribadian ekstrovert.

Aspek kepribadian merupakan sebuah aspek yang menjadikan penentu keunikan dan memberikan warna yang khas antara 
satu individu dengan individu yang lain. Hasil penelitian ini menegaskan adanya perbedaan dalam proses manajemen emosi di tempat kerja yang dipengaruhi oleh faktor kepribadian. Seorang introvert orientasi jiwanya adalah ke arah dalam dirinya, suka menyendiri, membutuhkan waktu untuk penyesuaian diri, suka hidup teratur, perasaanya di bawah kontrol yang ketat, tidak suka perangsangan, suka hal-hal bersifat filosofi, sementara itu seorang extrovert orientasi jiwanya ke arah luar dirinya, sociable, membutuhkan orang lain diajak berpikir dan berbicara, agresif, suka perubahan, perasaanya tidak dibawah kontrol yang ketat, suka perangsangan. Hal tersebut menimbulkan adanya konsekuensi pada pengelolaan emosi pada wiraniaga. Wiraniaga yang cenderung introvert akan lebih dapat mengontrol perasaannya seperti apa yang dituntut oleh deskripsi pekerjaannya.

Hasil penelitian Nocita \& Stiles (dalam Kuntadi, 2004) menemukan bahwa baik seorang extrovert maupun introvert tampak memiliki kecenderungan tertentu. Seorang introvert lebih menyukai hal-hal bersifat teoritik, suka analisa, suka akan suatu kesimpulan, penemuan baru, diskusi. Sementara itu orang extrovert suka hal-hal sederhana, lebih senang mendengar orang lain bercerita daripada ia mempelajari sendiri, menghindari hal-hal rumit. Berdasarkan hasil penelitian tersebut dapat dijelaskan bahwa individu memiliki perbedaan untuk melakukan manajemen emosi di tempat kerja, hal itu disesuaikan dengan kondisi dirinya, yaitu tipe kepribadian yang lebih dominan.

Berdasarkan data hasil observasi dan wawancara dengan supervisor personalia di Department Store X, diketahui bahwa sejak awal masa bekerja, para wiraniaga telah mendapatkan berbagai pelatihan mengenai tata cara dan prosedur standar melayani pelanggan. Supervisor dan manajer operasional sebagai atasan subjek bahkan selalu melaksanakan briefing mengenai customer service sebelum para karyawan memulai kerja. Dilihat dari rerata lama kerja subjek, rata-rata subjek telah bekerja selama 2,5 tahun pada Departement Store $\mathrm{X}$, sehingga mereka sudah sadar bahwa perilakunya dalam bekerja sehari-hari, terkait dengan pelanggan akan mempengaruhi penilaian konsumen terhadap toko tempat mereka bekerja, sehingga mereka pada umumnya dapat dengan sadar melakukan manajemen emosi dengan memodifikasi perasaan. Namun demikian, dari hasil wawancara tersebut belum secara spesifik mendapati adanya pengaruh tipe kepribadian terhadap emotional labor. Dari hasil analisis data statistik dijumpai adanya perbedaan yang signifikan antara wiraniaga yang memiliki tipe kepribadian introvert dan ekstrovert dalam mengelola emotional labor-nya. Wiraniaga yang introvert lebih baik dalam melakukan manajemen emosi dalam pekerjaan daripada wiraniaga yang ekstrovert.

Hasil penelitian ini mendukung hasil penelitian Suyatno \& Wahyuningsih (2005) yang menemukan bahwa individu dengan tipe kepribadian introvert cenderung lebih mampu mengelola konflik daripada individu dengan tipe kepribadian ekstrovert. Emotional labor pada dasarnya merupakan proses pengelolaan emosi sesuai tuntutan pekerjaan, yang dapat dilakukan dengan cara surface acting dan deep acting (Hochschild, 2012). Surface acting merupakan keadaan seseorang meregulasi ekspresi emosinya dengan cara menyembunyikan maupun memalsukan emosinya, sementara deep acting yaitu keadaan seseorang secara sadar mengatur emosinya untuk dapat mengekspresikan suatu emosi tertentu sehingga ia benarbenar merasakan emosi tersebut.

Individu dengan tipe kepribadian introvert memiliki ciri bahwa perasaannya di bawah kontrol yang ketat, sehingga cenderung 
nampak lebih tidak ekspresif dibandingkaan dengan individu dengan tipe kepribadian ekstrovert. Oleh karena itu, subjek dengan tipe kepribadian introvert cenderung lebih dapat menyembunyikan perasaan pribadi yang dirasakan dan tidak menampilkannya kepada publik, dalam hal ini konsumen. Hal ini didukung dengan hasil penelitian Tews \& Glomb (2003) yang menyebutkan bahwa extraverssion dan neuroticism terkait dengan kemampuan mengekspresikan emosi positif dan negatif.

Penelitian ini memiliki keterbatasan dan dapat dijadikan sebagai bahan kajian bagi peneliti selanjutnya untuk dapat mengeksplorasi variabel emotional labor, sehingga diperoleh hasil yang komprehensif. Secara metodologis, terutama reliabilitas alat ukur perlu ditingkatkan agar lebih baik. Berkaitan dengan jumlah subjek, maka akan lebih baik bila dapat melibatkan jumlah subjek yang lebih banyak lagi.

\section{KESIMPULAN}

Berdasarkan hasil penelitian dan pembahasan yang dikemukakan dapat ditarik kesimpulan bahwa ada perbedaan emotional labor pada wiraniaga yang memiliki kecenderungan tipe kepribadian introvert dan extrovert. Rerata emotional labor wiraniaga dengan kecenderungan tipe kepribadian introvert lebih tinggi daripada wiraniaga yang memiliki kecenderungan tipe kepribadian extrovert $\left(M_{\text {introvert }}=36,08\right.$; $\left.M_{\text {extrovert }}=33,67 ; t=3,50 ; p=0,001\right)$.

\section{DAFTAR PUSTAKA}

Berry, L. L. (2000). Cultivating service brand equity. Journal of the Academy of Marketing Science, 28(1), 128-137

Brotheridge, C. $\mathrm{M}$ \& Grandey, A. A. (2002). Emotional labor and burnout:
Comparing two perspective of "people work". Journal of Vocational Behavior 60, 17-39

Cho, Y., Rutherford, B. N., Park, J. (2013). Emotional labor's impact in a retail environment. Journal of Business Research, 66(1), 2338-2345

Collishaw, M. A., Dyer, L, \& Boies, K. (2008). The authenticity positive emotional displays: Client responses to leisure service employee. Journal of Leisure Research, 40, 1, 23-46.

Grandey, A. A. (2000). Emotion regulation in the workplace: A new way to conceptualize emotional labor. Journal of Occupational Health Psychology, 5,1,95-110

Hall, C. S., \& Lindzey, G. (1999). Theories of personality. New York: John Wiley and Sons, Inc.

Hochschild, A. R. (2012). The managed heart: Commercialization of human feeling. California. University of California Press.

Johnsons, H. M. (2004). The story behind service with a smile: The effects of emotional labor on job satisfaction, emotional exhaustion, and affective wellbeing. Unpublished Master of Arts thesis. Departement of Psychology. College of Art and Sciences. University of Florida.

KBBI Online. (2012). Diakses melalui kbbi.web.id/wiraniaga, pada 11 Juni2015

Kuntadi, H. (2004). Gaya pengambilan keputusan ditinjau dari tipe kepribadian. Tesis Tidak Dipublikasikan. Yogyakarta: 


\section{Universitas Gadjah Mada}

Modekurti-mahato, M., Kumar, P., \& Raju, P. G. (2014). Impact of Emotional Labor on Organizational Role Stress A Study in the Services Sector in India. Procedia Economics and Finance, 11(14), 110-121. doi:10.1016/S2212-5671(14)00181-6

Nurdiyani, I. (2009). Hubungan antara emotional labor process (surface acting dan deep acting) terhadap employee wellbeing pada perawat instalasi rawat inap RS X wilayah Surabaya. Skripsi Tidak Dipublikasikan. Surabaya: Universitas Airlangga

Permata, N. (2007). Dinamika manajemen emosi sesuai tuntutan kerja (emotional labor) pada karyawati penjualan dan promosi. Skripsi Tidak Dipublikasikan. Yogyakarta: Universitas Gadjah Mada

Suryabrata, S. (2002). Psikologi kepribadian. Jakarta: PT Raja Grafindo Persada

Suyatno, N. \& Wahyuningsih, H. (2005). Perbedaan manajemen konflik antara tipe kepribadian ekstrovert dengan introvert. Skripsi Tidak
Dipublikasikan. Yogyakarta: Fakultas Psikologi Universitas Islam Indonesia

Tews, M. J, \& Glomb, T. M. (2003). Emotional labor and the five factor model of personality. Working paper series No.04-01-03. New York: The Center for Hospitality Research School of Hotel Administration Cornell University. Diakses melalui https://www.hotelschool.cornell.edu/c $\mathrm{hr} / \mathrm{pdf} / \mathrm{showpdf} / \mathrm{chr} /$ research/working/ laborfivefactor.pdf?t=CHR\&my_path _info=chr/research/working/laborfive factor.pdf

Torland, M. (2012). Emotional labour and the job satisfaction of adventure tour leaders in Australia. Unpublished Dissertation. Southern Cross University, Australia. Retrieved from http://epubs.scu.edu.au/cgi/viewconte nt.cgi ?article $=1305 \&$ context $=$ theses

Zapf, D. (2002). Emotion work and psychological well-being: A review of the literature and some conceptual considerations. Human Resource Management Review, 12, 237-268. 